mother; recent experience. In: Sutherland HW, Stowers JM, eds. Carbohydrate metabolism in pregnancy and the newborn. Edinburgh: Churchill Livingstone, 1984:144-9.

4 Mestyan J, Saltes FG, Schultz K, Howarth M. Hyperaminoacidaemia due to the accumulation of gluconeogenic amino acid precursors in hypoglycaemic small for gestational age infants. $J$ Pediatr 1975;87:409-14.

${ }^{5}$ Mestyan J, Schultz K, Soltesz G, Howarth M. The metabolic effects of glucagon infusion in normoglycaemic and hypogly- caemic small for gestational age infants II. Changes in plasma amino acids. Acta Paediatr Acad Sci Hung 1976;17:245-53.

${ }^{6}$ Bloom SR. Glucagon. Br J Hosp Med 1975;13:150-8.

Correspondence and requests for reprints to Dr P E Carter, Royal Aberdeen Children's Hospital, Cornhill Road, Aberdeen AB9 2ZA.

Accepted 5 April 1988

\title{
Acute pneumonia in Zimbabwe: bacterial isolates by lung aspiration
}

\author{
M O IKEOGU \\ Department of Paediatrics, Mpilo Central Hospital, Bulawayo, Zimbabwe
}

SUMMARY Forty children, aged 2 months to 11 years, with severe acute pneumonia were investigated by needle aspiration of the lung. Fourteen organisms were isolated in only 13 patients. Streptococcus pneumoniae was isolated in six patients, Staphylococcus aureus in three, and Haemophilus influenzae in two. Two patients had mixed organisms.

Severe acute lower respiratory infection is common in developing countries and is a major cause of mortality. Studies from some developing countries indicate a high prevalence of bacteria in the aetiology of pneumonia in hospitalised children. ${ }^{12}$ This may not be universally the case. The present study was aimed at determining whether bacteria are the dominant cause of pneumonia in children in $\mathrm{Zim}$ babwe as has been found in some developing countries.

\section{Patients and methods}

The study was conducted between February and August 1987. All children admitted under one of the three paediatric firms with severe pneumonia were investigated by needle aspiration if they had not received any antibiotics before admission. The needle aspiration was performed according to a standard method with slight modification. ${ }^{3}$ The aspirate was cultured on blood and chocolate agar, and tryptose phosphate or brain-heart infusion broth. The positive growths were indentified by standard bacteriological methods. Initially negative cultures were subcultured for 10 days.

In the period under consideration 153 children were discharged with a final diagnosis of either lobar pneumonia or bronchopneumonia. Of these 40 qualified for lung aspiration and had the procedure carried out. All were between the ages of 2 months and 11 years. All had a history of respiratory infection of less than five days' duration. The extent of the consolidation was determined by physical examination and confirmed on a chest radiograph and involved at least a whole lobe.

\section{Results}

Fourteen bacterial organisms were isolated by lung aspiration from 13 children amounting to a positive isolation rate of $32.5 \%$. Of the single isolates the dominant organism was Streptococcus pneumoniae, which was isolated in six patients, followed by Staphylococcus aureus in three, and Haemophilus influenzae in two. Two patients had mixed organisms, one with $S$ pneumoniae and $H$ influenzae and another with $S$ aureus and Mycobacterium tuberculosis. The $M$ tuberculosis was isolated from sputum culture.

There were no deaths attributable to lung aspiration. The only death in the series was an 18 month old child with severe kwashiokor and right upper lobe pneumonia due to $H$ influenzae and large intracerebral abscess presumably due to the same organism. One patient had slight haemoptysis that cleared within 30 minutes, and another had a small pneumothorax that cleared spontaneously.

\section{Discussion}

Needle aspiration of the lung is the only definitive way of establishing the bacterial organism responsible for acute pneumonia. Studies from developing countries using this technique have established beyond doubt the dominant role of bacteria in the aetiology of acute pneumonia in hospitalised children. ${ }^{124}$ This, together with widespread mal- 
nutrition, had led to the almost universal use of antibiotics, often in broad spectrum combinations, in the treatment of most children with lower respiratory tract infection in and outside hospitals even when the clinical findings strongly suggest a viral aetiology. This practice has serious economic consequences for these poorer countries considering the large numbers of children seen with respiratory infections in and outside hospitals. It no doubt reflects the frustration of the doctor confronted with inadequately investigated lower respiratory infection in a sick child who is often in severe respiratory distress. Not least is the problem of emergence of resistant bacterial strains where antibiotics are used widely. The paucity of information from many developing countries regarding the aetiology of acute lower respiratory infection in children makes rationalisation of treatment difficult.

The result of this small series suggest that bacterial infection is not the most common cause of pneumonia in Zimbabwe in contrast with other developing countries such as Nigeria, ${ }^{1}$ Papua New Guinea, ${ }^{2}$ and Chile $^{4}$ where most pneumonias in hospitalised children are caused by bacteria. Comparing these countries with high bacterial prevalence important regional differences in the bacteriological pattern become apparent. For instance, in Papua New Guinea $H$ influenzae dominates over $S$ pneumoniae as the cause of pneumonia in children and $S$ aureus was conspicious by its total absence, whereas in Santiago, Chile, $S$ aureus was by far the commonest organism isolated. In Nigeria $S$ pneumoniae accounted for $62 \%$ of the isolates.

It is therefore clear that information obtained in one region may not necessarily be applicable to other areas. To be able to rationalise treatment and make recommendations knowledge of the bacteriological pattern and bacterial sensitivities in the particular area is essential. Identification of areas of low bacterial prevalence would also mean for governments in those areas more money spent on means of providing supportive care in hospitals if there is to be any substantial reduction in mortality due to lower respiratory infections in children, particularly in infants.

The value of lung aspiration in acute lower respiratory infection is beyond question. The technique is easy and safe and undoubtedly superior to sputum, nose and throat swabs, and aspirates from the tracheobronchial tree. ${ }^{125}$ It enables not only the exact identification of the causative bacterial organism but also the determination and monitoring of antibiotic sensitivity. The morbidity of the procedure is small and usually minor as is evident from this study and those of others. ${ }^{124}$ In children with negative bacterial growth, which implies in most cases acute viral infection, the therapeutic emphasis will have a shift towards supportive care if these often very sick children are to survive.

\section{References \\ 1 Silverman M, Stratton D, Diallo A, Eglier LJ. Diagnosis of acute bacterial pneumonia in Nigerian children. Value of needle aspiration of lung and countercurrent immuno-electrophoresis. Arch Dis Child 1977;52:925-31. \\ 2 Shann F, Germer S, Hazlett D, Gratten M, Linnermann V, Payne R. Aetiology of pneumonia in children in Goroka Hospital, Papua New Guinea. Lancet 1984;ii:537-41. \\ 3 Hughes WT, Buescher ES. Pediatric procedures. Philadelphia: WB Saunders, 1980. \\ 4 Mimica I, Donoso E, Howard JE, Ledermann GW. Lung puncture in the aetiological diagnosis of pneumonia. A study of 543 infants and children. Am J Dis Child 1971;122:278-82. \\ 5 Barret-Conner $F$. The non-value of sputum in the diagnosis of pneumococcal pneumonia. Am Rev Respir Dis 1971;103:845-8.}

Correspondence to Dr M O Ikeogu, Department of Pediatrics, Mpilo Central Hospital, P O Box 2096, Bulawayo, Zimbabwe.

Accepted 10 April 1988 